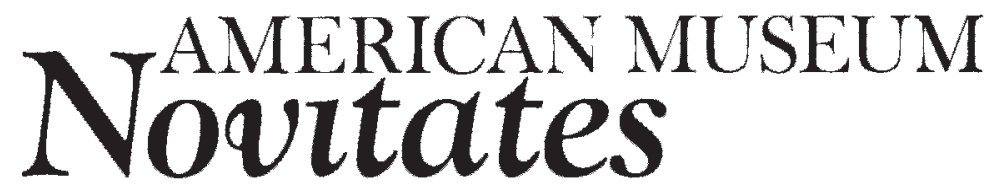

PUBLISHED BY THE AMERICAN MUSEUM OF NATURAL HISTORY CENTRAL PARK WEST AT 79TH STREET, NEW YORK, NY 10024 Number 3632, 12 pp., 21 figures

December 31, 2008

\title{
The Solitary Bee Calliopsis zebrata: Biological and Distributional Notes and Description of Its Larva (Hymenoptera: Andrenidae: Panurginae)
}

JEROME G. ROZEN, JR. ${ }^{1}$

\begin{abstract}
Calliopsis (Macronomadopsis) zebrata zebrata Cresson, collected from Astragalus gracilis Nutt., is reported from central Oklahoma, the most eastern locality for those Calliopsis with yellowbanded metasomas (i.e., Nomadopsis, s.1.). A long series of males and females of C. z. bobbae Rozen, associated with Astragalus humistratus A. Gray from Flagstaff, Arizona, permits an expanded description of that subspecies, comparing it with C. z. zebrata. Presented information on its nesting biology and mating behavior shows that these features are similar to those of the other species of Macronomadopsis whose biology is known. Mature larvae of both subspecies are described for the first time and compared with each other. This shows that they are essentially identical and differ little from those of other Macronomadopsis and even Nomadopsis s.l. The first SEM pictures of any panurgine larva reveal unexpected details of integumental sculpturing. Earlier studies of adults of this species demonstrated extensive geographic variability, as do adults from Oklahoma. Additional collections of this species throughout its range are needed to analyze population boundaries.
\end{abstract}

\section{INTRODUCTION}

This paper presents new information on the distribution and geographic variation of Calliopsis (Macronomadopsis) zebrata Cresson and describes its biology and mature larva. This species was formerly assigned to the genus Nomadopsis with other Nearctic Cal- liopsis species having pale metasomal markings. When I revised Nomadopsis (Rozen, 1958), C. zebrata seemed to have a montane distribution restricted to high elevations in the western part of the United States. The eastern boundary of its range was basically the eastern edge of the Rocky Mountain uplift (Rozen, 1958: map 8). Other Macronomadop-

\footnotetext{
${ }^{1}$ Division of Invertebrate Zoology, American Museum of Natural History (rozen@amnh.org).
} 

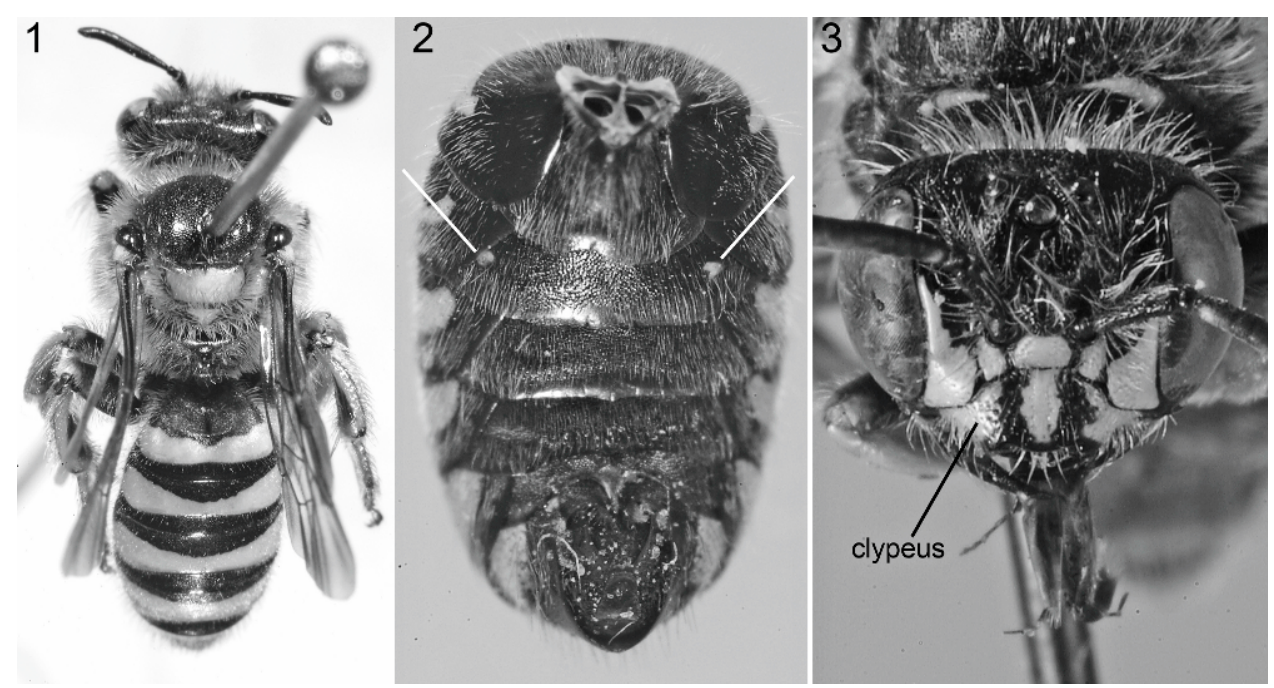

Figs. 1-3. 1-2. Macrophotograph of adult Calliopsis zebrata bobbae from Flagstaff, Arizona. 1. Dorsum of female, showing well-developed yellow maculations on mesoscutellum and metanotum. 2. Male metasomal showing paired yellow spots (leaders) on metasomal sternum 2. 3. Face of adult female of C. $z$. zebrata from Oklahoma showing dark clypeal marks, which on other specimens from same locality can be less or more extensive.

sis $^{2}$ known at that time and two more species described since are also from the same geographic region, although some are clearly not montane. At the time of the revision, I recognized and named a subspecies, $C . z$. bobbae Rozen, from the highlands of northcentral Arizona; it is characterized by more extensive yellow markings on its meso- and metasomas and appendages (figs. 1,2) than found on the other (i.e., nominate) subspecies, as detailed below. Until now it has been known only from the type series and a handful of scattered specimens examined after the subspecies was described. The mature larva of neither subspecies has been described.

So far as known, all species Macronomadopsis are legume feeders: $C$. micheneri

\footnotetext{
${ }^{2}$ Although Michener (2000) synonymized Macronomadopsis with Nomadopsis, I continue to recognize the two taxa for the time being, partly because of their apparent differences in mating behavior, as well as of their differences in genitalic structure. Each seems to be a distinctly monophyletic group. Until the genus Calliopsis is examined cladistically, we will not have a reasonable understanding of the relationships of its numerous subgenera and species of uncertain assignment. Interestingly, all Macronomadopsis so far as known are oligoleges of Fabaceae; species of Nomadopsis s.s. are oligolectic on a wide assortment of plant families, but none visits Fabaceae.
}

Rozen, C. anthidia Fowler, and C. filiorum Rozen appear to be oligoleges of Trifolium (Fabaceae), the host plant of C. barri Rozen is uncertain (Rozen, 1959), and C. zebrata visits Astragalus (Fabaceae) for larval provisions.

Some years ago I received from Charles D. Michener 14 specimens of Calliopsis z. zebrata that he had collected on Astragalus gracilis Nutt. and three mature larvae from its nesting site. He had found these at Roman Nose State Park, Watonga, Blaine Co. (N 35 56'15', W $98^{\circ} 25^{\prime} 55^{\prime \prime}$ ), el. 1450-1550 ft, V-18-1977, in central Oklahoma. This was a remarkable distributional record because not only was it far east of the known range of the species and well removed from high elevations, but it was also east of the ranges of any of the 39 known species of Nomadopsis s.1.

Michener (personal commun., Oct. 4, 2007) recalled his collecting Calliopsis z. zebrata from his discovery in Oklahoma 30 years earlier, "The Astragalus was in a prairie area. The nests were in a road or path that went into the prairie and were in steeply sloping bare earth at the side of the road or path.'

Although I originally intended to discuss this discovery in a planned review of Calliopsis, Margaret A. Rozen, Kenneth C. Rozen, and I visited our family burial plot in 
the Flagstaff Citizens Cemetery in Flagstaff, Arizona, on August 13, 2007, and Margaret discovered a nesting site of C. z. bobbae within $30 \mathrm{ft}$ of the graves of her great-great-grandfather and -grandmother and a number of other relatives. The study of this site augmented information about the little known biology of this species (Cockerell, 1915; Hicks, 1936), which I had not studied before, so that it seems worthwhile to address both its biology and distribution now. From this site, we were able to retrieve over 60 adults, eight mature larvae, and a specimen of the host plant, Astragalus humistratus A. Gray (fig. 6). I observed the bees' mating behavior and was able to excavate their nests and compare them with those of other Macronomadopsis.

\section{Re-Description of Adults of CALLIOPSIS ZEBRATA BOBBAE}

\section{Figures 1-3}

The large sample of adults of Calliopsis $z$. bobbae from Flagstaff permits a more complete understanding of the range of color pattern than presented by Rozen (1958). In the following re-description, the most diagnostic characters are in boldface, whereby members of this population can be distinguished from those currently assigned to $C$. $z$. zebrata. Parenthetical remarks refer to C. z. zebrata.

MALE: Outer (anterior) surface of scape with broad yellow stripe (stripe tending to be narrower); pedicel with or without yellow spot on outer surface (pedicel without yellow spot); first flagellomere with conspicuous yellow outer surface concolorous with that of scape (often surface only as pale as following flagellomeres). Lateral angles of pronotum each with large yellow maculation (maculation smaller to absent); lateral pronotal lobes each with small to large yellow maculation (usually dark). Mesoscutum (as in fig. 1) usually with small to large yellow maculation, sometimes covering entire sclerite (invariably dark); metanotum (as in fig. 1) often with yellow maculation (invariably dark). Tegula with yellow maculation (often without yellow maculation). Legs with extensive yellow maculations, so that middle and hind femora each with yellow ventral stripe extending to, or almost to, base (yellow maculations more or less reduced, so that middle and hind femora with yellow restricted to apices); anterior surface of hind tibia yellow (sometimes with large dark area occupying middle of surface). Dorsal metasomal bands broad, never interrupted sublaterally (often narrow, sometimes so narrow that sublateral dark spots interrupt band on first segment); second (occasionally also third) metasomal sternum (fig. 2) with small to very small, often irregularly shaped yellow lateral spot on each side (spots absent except in Oklahoma males).

Female: Scape with narrow yellow stripe on outer surface to completely dark (completely dark). Subantennal areas light (sometimes dark); clypeus completely yellow except for pair of transparent brownish spots characteristic of both sexes (with pigmented, variablesized, opaque dark maculations [fig. 3], which darken center of clypeus beneath supraclypeal area on some specimens). Lateral pronotal angles, each with large yellow maculation (maculation reduced to absent); lateral pronotal lobes yellow or at least with yellow spot (usually dark). Tegula with anterior yellow maculation (usually dark, without yellow). Mesoscutellum (fig. 1) usually with small to large yellow maculation, sometimes covering entire sclerite (invariably dark); metanotum (fig. 1) sometimes with median maculation (invariably dark). Legs with more extensive yellow maculations so that dorsal surface of midtibia mostly yellow (less extensive yellow maculations, so that dorsal surface of midtibia occasionally primarily dark). Dorsal metasomal yellow bands wide, so that lateral parts of band of tergum 5 fused or at least contiguous (often separated medially).

Material Examined: 4 males, USA: AZ: Coconino Co.: Flagstaff, N35 $11^{\prime} 9^{\prime \prime}$, W11 $1^{\circ} 39^{\prime} 4^{\prime \prime}$, 6971 ft, VIII-13-2007 (M.A., K.C., J.G. Rozen); 32 males, 10 females, same except VIII-14-2007 (M.A., J.G. Rozen); 7 males, 14 females, same except VIII-30-2007 (J.G. Rozen); 2 males, same except VIII-7-9-1959 (K.V. Krombein); 1 male, same except Mormon Lake, $7000 \mathrm{ft}$, VII-8-151956 (F.G. Werner) Astragalus humistratus.

Remarks: As noted earlier (Rozen, 1958), C. zebrata exhibits considerable geographic variation in color pattern, and $C$. $z$. bobbae has the most extensive pale markings of all samples found to date. However, the variabil- 
ity of $C$. z. zebrata as now defined deserves further analysis based upon more extensive collections so that we can understand the range of variation of its populations. The sample of eight males and six females collected by Michener in Oklahoma is a case in point. Although the females have dark clypeal pigmentation and reduced yellow markings on their pronotal angles and legs, their tegulae are yellow at the base and one has a small yellow mark on its pronotal lobes. Furthermore, males have rather extensive yellow on their pronotal lateral angles and lobes and yellow lateral spots on their metasomal sternum 2, as do males of $C$. z. bobbae. None of the individuals display yellow on their mesoscutellum or metanotum. Obviously the sample comes from the eastern edge of the species range whereas $C . z$. bobbae is from the extreme western edge of the range despite the males' sharing these features in common. After a broad analysis of the geographic variation is conducted, we will have a better understanding of the nature and distribution of this variation and can determine whether it is reasonable to recognize the two subspecies. Also, as one reviewer pointed out, DNA data might be desirable here for delineating species, subspecies, and population boundaries.

\section{Biology of CALLIOPSIS ZEBRATA BOBBAE}

Figures 4-7

MAting: Margaret first observed males of this species flying swiftly close to the ground in an area soon discovered to be the nesting site. She also saw several individuals (presumably females) as they descended into burrows. When I picked up a specimen, I was able to identify the species because of its yellow mesoscutellum. On our return the following day, we observed the extensive activity of numerous males flying close to the ground and many mating encounters of males and females tumbling on the ground, usually with a number of males attempting to copulate with a single female. We often collected mating pairs with our fingers. When I returned to the site on August 30, 2007 (16 days later), females were still nesting, and males, though less common than earlier, were still looking for mates. Although mating occurs at the nesting site, the area was also supplied with scattered host plants that females occasionally visited. Thus, one cannot make a distinction between mating at the nesting site as opposed to mating at the flowers. No couples were observed flying in copula.

Cockerell's (1915) description of the swift flight of male $C$. z. zebrata was almost certainly mating behavior because it is identical to our observations of the mating of $C . z$. bobbae. Rozen's (1958) accounts of the matings of $C$. anthidia and $C$. micheneri agree completely with that of $C . z$. bobbae. Thus it would not be surprising if mating of all Macronomadopsis species were similar. This behavior differs from what is known about the species of the subgenus Nomadopsis, most species of which are known to fly in copula rather to initiate brief mating bouts while tumbling over the ground (Rozen, 1958).

Description of Nest: The nesting site of Calliopsis z. bobbae consisted of scattered nests in a horizontal area of sparse, low vegetation exposed to the sun most of the day through a partly open canopy of tall trees (fig. 4). The bees generally excavated nests in the bare spots between the plants (fig. 5). The plants were grasses and the decumbent host plant that was widely scattered throughout the area. The site was at least $6 \mathrm{~m}$ in diameter, but its exact shape and size were uncertain because of daily showers that obscured nest entrances from day to day and because some of the entrances were in surrounding, more vegetated areas. This site was not unusual compared with the nesting sites of other Macronomadopsis that I have studied, except I cannot remember a site where the host plant was widely dispersed among the nest entrances. The soil was sandy, without large rocks, and moist because of the showers.

Nest entrances were surrounded by fresh tumuli resulting from females' having to dig out tunnels filled with soil from the rain of the previous day on each of our three study visits. Main tunnels descended more or less vertically; one measured $5.5 \mathrm{~mm}$ in diameter. Cells, ranging in depth $5.5-11 \mathrm{~cm}$, were subhorizontal with the front end slightly higher than the rear. They were arranged singly (i.e., not in linear series), each connected to the main tunnel by a moderately short, soil-filled 

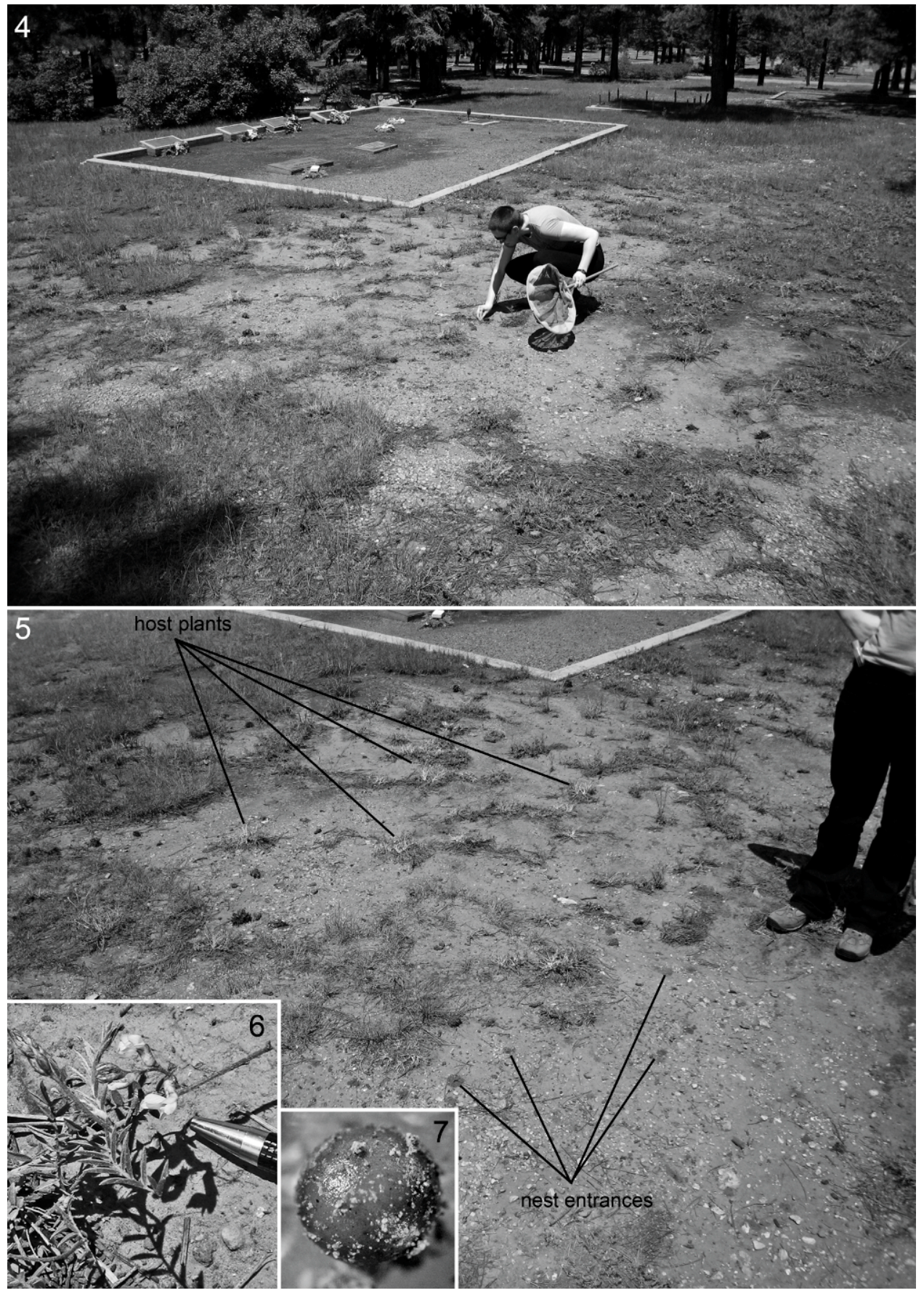

Figs. 4-7. 4. Margaret collecting mating pairs of Calliopsis zebrata bobbae by hand at nesting site, the more-or-less barren surface in the foreground. 5. Close-up of nesting surface, with lower leaders pointing to some (among many) nest tumuli and upper leaders pointing to some (among many) food plants. 6. Close-up of flowering Astragalus humistratus. 7. Provision sphere. 
lateral. Thus, nest architecture was essentially the same as that diagrammed by Rozen (1958: fig. 63) for Calliopsis a anthidia.

Cell closures, $4.5 \mathrm{~mm}$ in diameter on the inside, were a somewhat concave spiral of four coils to the radius. Cells were approximately $7.5 \mathrm{~mm}$ in maximum diameter and $13 \mathrm{~mm}$ long. The cell walls were slightly smoother and shinier in the rear than in the front, although the linings at best were faint. When tested with a water droplet, the surface was waterretardant. Feces in cells containing hibernating larvae were placed at the rear of the cell, as typical for all known Calliopsis. Vacated cells were backfilled by the newly departing inhabitant. The presence of such cells indicates that the site had been used by the previous generation. In general there were no features of the nest that could distinguish it from that of related species.

Hicks's (1936) report on the nesting biology of Calliopsis z. zebrata, though lacking in some comparable details, is entirely consistent with that of $C$. $z$. bobbae.

Provisioning: Females of Calliopsis $z$. zebrata transport pollen as a moist mass surrounding their hind tibiae. The pollen of Astragalus humistratus has a brown tinge, a color that is also imparted to the spherically shaped, completed provisions. Two food spheres were 3.8 and $4.3 \mathrm{~mm}$ in diameter, and, like those of other known species of Calliopsis, they are coated with a shiny, clear, waterproof coating (fig. 7).

TEMPORAL Distribution: The reported temporal flight range for Calliopsis zebrata is June 3 to August 23 (Rozen, 1958). Michener found the nesting site of Calliopsis z. zebrata on May 18, 1977. The Flagstaff site of C. $z$. bobbae was discovered and visited on August 13 and 14, 2007, and revisited on August 30, 2007, when the nests were excavated. There is no evidence that this species or any other species of Macronomadopsis has more then one generation per year. Because adult populations of bees generally are active for a month or so, local populations may be synchronized with the availability of their pollen plants and, in turn, to climatic conditions that support flowering. Such temporal as well as geographic isolation of populations of a species may promote endemism and the development of distinct color patterns among conspecific populations, as seems to be the case here.

Hicks's (1936) observations of even earlier emergences of adults of Calliopsis z. zebrata were based on larvae collected in wintertime and retained "at slightly above room temperature" in the laboratory before they emerged.

Cleptoparasitism: A single female of Triepeolus pectoralis (Robertson) (Apidae: Nomadinae). (Apidae, Nomadinae) was observed while I excavated nests on August 30, 2007. Since it was not searching the ground for nest entrances, it was probably not a cleptoparasite of this species. According to Rightmyer (2006), it has been reported to attack nests of Melissodes druriella (Kirby) (Apidae). No cleptoparasitic larvae were found in brood cells. Of known Oreopasites (Apidae: Nomadinae), a genus associated with many species of Calliopsis, only $O$. vanduzeei Cockerell is a confirmed parasite of any Macronomadopsis; its single host species is $C$. anthidia (Rozen, 1992).

\section{Description of Mature Larva of CALLIOPSIS ZEBRATA}

Figures 8-21

The following larval description of Calliopsis zebrata is based on both the predefecating and postdefecating forms. It is quite similar to the description of the yellowbanded Calliopsis (i.e., Nomadopsis, s.1.) presented by Rozen (1958). The terminology has been updated to reflect current anatomical usage, and the presentation has been formatted somewhat differently. Except for details of integumental sculpturing now possible through SEM examination, the description seems to be applicable to all species the larvae of which are known. Thus, it will probably be of little value in distinguishing between species or even subgenera, since larval differences between them apart from size are subtle at best. Perhaps when the surface sculpturing of other species is studied by SEM, diagnostic features will be discovered. No differences were found whereby postdefecating larvae of the two subspecies could be differentiated.

Specimens examined for viewing with the Hitachi S-5700 scanning electron microscope (SEM) were critical-point dried and coated 

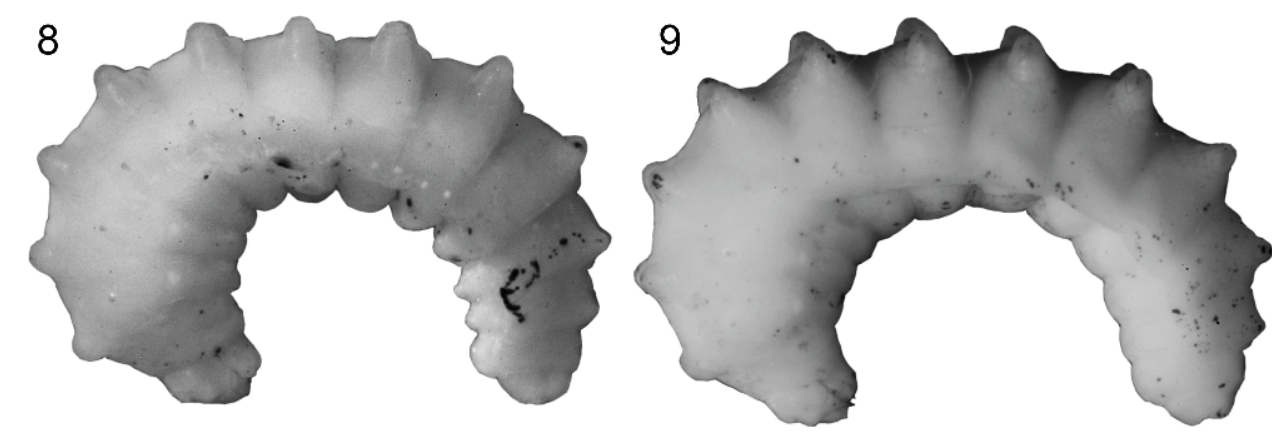

Figs. 8-9. Macrophotographs of preserved mature larvae, lateral view, of Calliopsis z. bobbae (left) and C. z. zebrata (right).

with gold/palladium. Others were studied with a Zeiss EVO 60 SEM. Still others, after heads were severed from bodies, were cleared in an aqueous solution of sodium hydroxide, washed, transferred to ethanol, stained with Chlorazol Black E until lightly colored, and examined in glycerin with stereomicroscope and compound microscope to identify internal head ridges and tentoria.

A major problem when examining the postdefecating larva with an SEM was the extensive coating of the dried, transparent secretion that covered them. The coating material, of uncertain origin, is secreted by larvae of many bee taxa when they enter diapause and presumably protects the individual from desiccation. This material obscures fine surface features when they are coated with gold/palladium. Specimens, when first cleared in an aqueous solution of sodium hydroxide, seem to lose some of this coating, but, as can be seen in figure 13, the labiomaxillary region remains coated even after the head has been completely cleared in the boiling aqueous solution. This coating is not seen on the prothorax of the same specimen (figs. 11, 12), perhaps suggesting that it did not reach that part of the anatomy or that it was much more thinly applied there than in the labiomaxillary area, alluding to the possibility that its origin might be the salivary gland.

The single predefecating larva collected was first cleared, stained, and then examined with both compound and stereomicroscopes. Its head was then critical-point dried, coated, and studied with the Hitachi SEM. As anticipated, it had not yet been coated with the diapausing secretion (compare figs. 13 and 20). I ques- tioned whether the intensive preparation of this specimen might have adversely affected its integument, but a comparison with the less harshly treated postdefecating larval head (fig. 1) differs little from the predefecating head (fig. 19) and suggests little difference between the two. Thus, close-up SEM micrographs of the mouthparts (figs. 20, 21) would seem to show the true verrucosity of the labiomaxillary region.

The following description refers to all known mature larvae of Calliopsis zebrata.

HEAD: Integument with scattered sensilla that are not setiform; dorsal surfaces of maxilla and hypopharynx densely spiculate (fig. 21); lateral surfaces of epipharynx spiculate; integument particularly of maxillary apices, labial apex, and hypopharynx but also most of head capsule wrinkled and with hypopharynx and apex of labiomaxillary region deeply verrucose (figs. 10, 13, 19-21). Integument unpigmented except for mandibular apices.

Head (figs. 10, 13, 18-21) moderate in size compared with body size; head capsule distinctly wider than length measured from top of vertex to lower clypeal margin in frontal view. Tentorium complete, including dorsal arms, but thin. Anterior tentorial pit well removed from anterior mandibular articulation (figs. 10, 19); posterior tentorial pits in normal position; postoccipital ridge uniformly moderately developed; median longitudinal thickening of head capsule (coronal ridge) absent; hypostomal ridge moderately developed, its posterior section curving inward abruptly to meet tentorial bridge while dorsal ramus continues posteriorly and fades; pleurostomal ridge moderately developed; episto- 

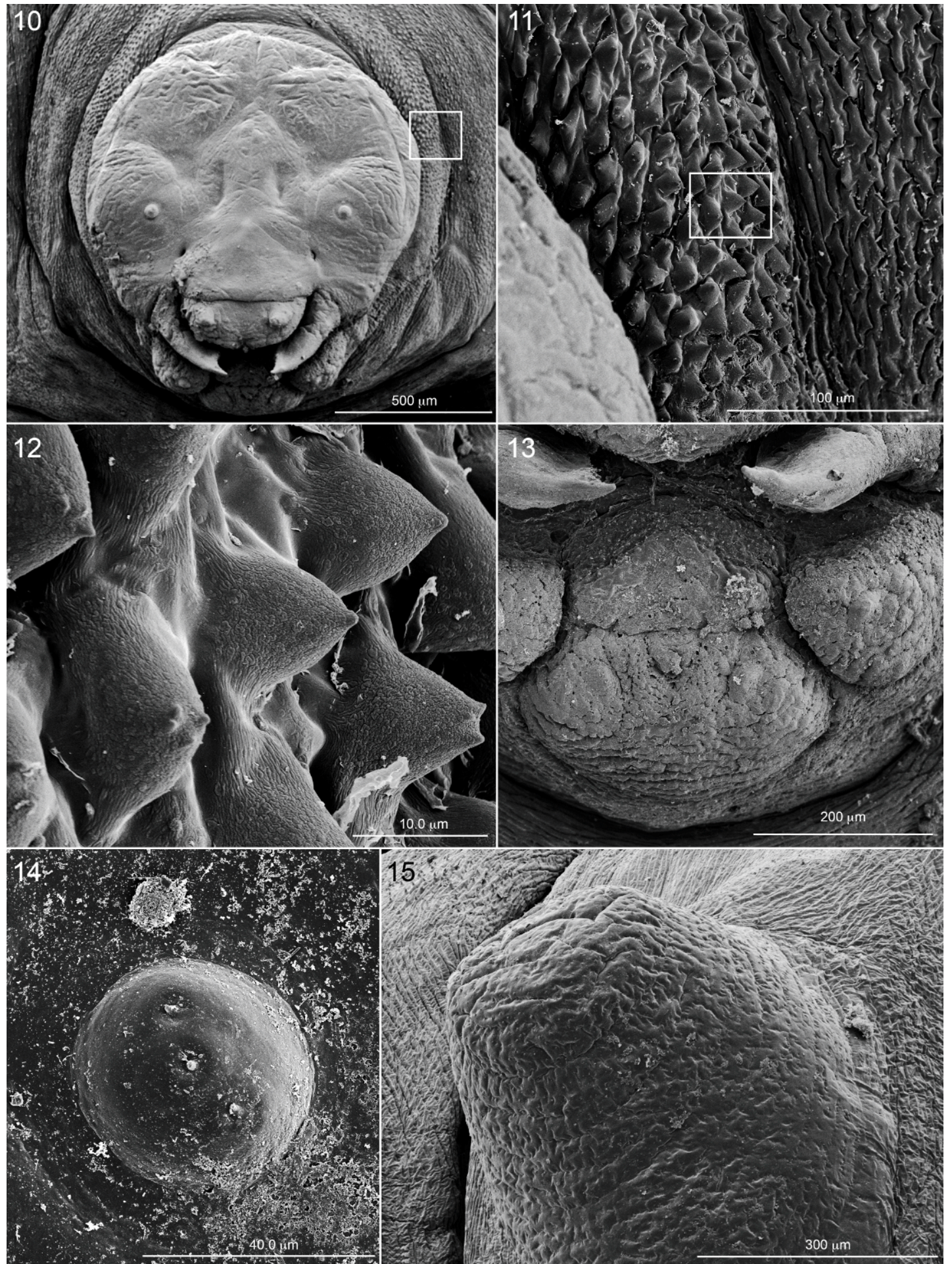

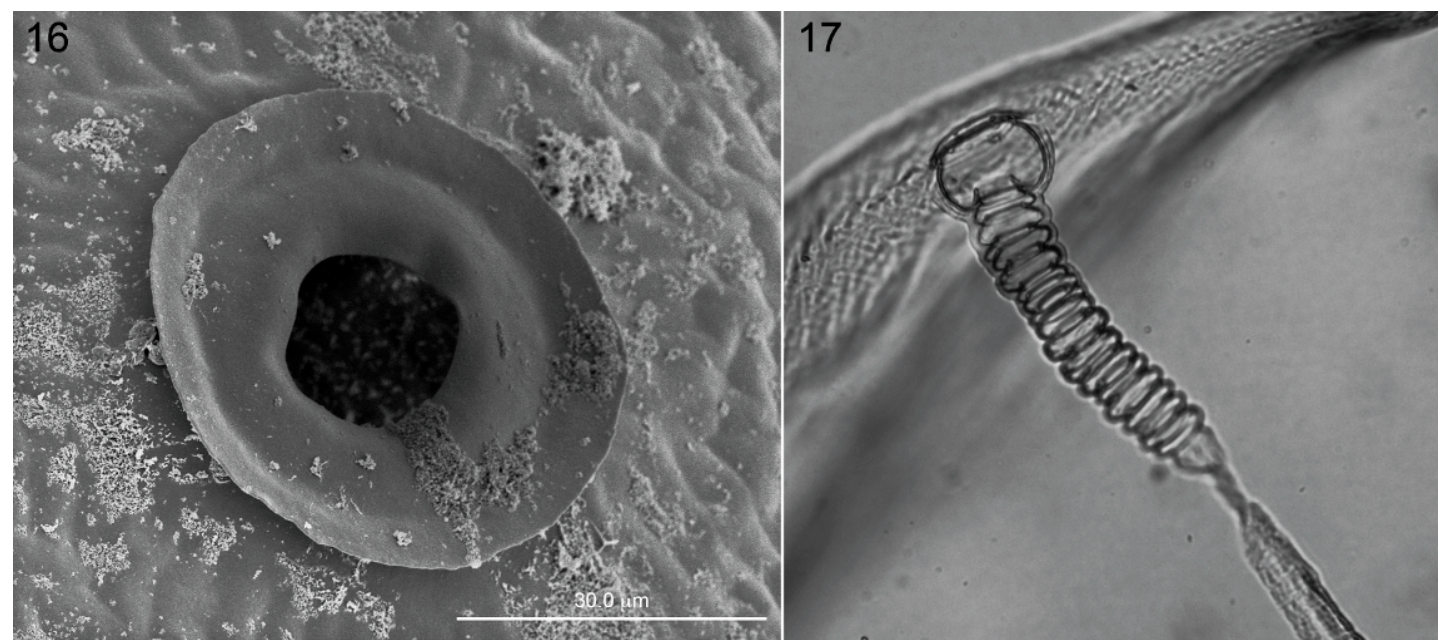

Figs. 16, 17. Larval spiracle of Calliopsis z. bobbae. 16. SEM micrograph of spiracular peritreme with elevated rim of postdefecating form, external view. 17. Macrophotograph of entire spiracle of predefecating form, lateral view.

mal ridge laterad of (below) anterior tentorial pit moderate in length; ridge between pits absent. Parietal bands evident as integumental scars (figs. 10, 19). Antennal prominence rather weak (fig. 19); antennal disc as seen on cleared specimen moderately small, its diameter about one-half distance from its lowest rim to center of anterior tentorial pit (distances measured in maximum profile); antennal papilla projecting weakly, its height less than one-half basal diameter, each bearing 3 to 4 sensilla (fig. 14). Vertex evenly rounded, moderately broad, as seen from side (fig. 18), without projections. Labrum projecting anteriorly as far as clypeus in lateral view (fig. 18), moderately long in frontal view, apically rounded, spiculate laterally, and with pair of acutely pointed, sensilla-bearing tubercles (figs. 10, 18, 19); epipharynx with median cluster of sensilla near front edge.

Mandible (approximately as in Rozen, 1958: figs. 34, 35) in outer or inner views tapering evenly to narrowly pointed apex; dorsal apical edge with linear row of sharp teeth (fig. 21) that broadens out at cusp; ventral apical edge with teeth that are fewer and smaller than those of dorsal apical edge; cusp weakly produced in dorsal and ventral views; apical concavity shallow, facing hypopharyngeal surface; outer mandibular surface with small, seta-bearing tubercle toward base; dorsal surface finely spiculate. Labiomaxillary region weakly projecting in lateral view (fig. 18), so that its apex exceeded by apex of labrum in lateral view; apex of maxilla projecting as far as or slightly farther than apex of labium in lateral view (fig. 18). Cardo, stipes not evident as sclerites although cardostipital articulation suggested by external folding of integument; articulating arm of stipital sclerite not evident although hypopharyngeal groove pronounced; maxillary palpus (fig. 21) positioned at apex of maxilla, small, shorter than basal diameter, somewhat ob-

Figs. 10-15. SEM micrographs of postdefecating larva of Calliopsis z. bobbae, cleared by being boiled in aqueous solution of sodium hydroxide. 10. Head, frontal view, 11. Prothorax showing dense pattern of spiculation identified by rectangle in fig. 10. 12. Close-up of spicules identified by rectangle in fig. 12; note acute apical projections. 13. Left side of labiomaxillary region, frontal view, showing coating that failed to be removed after head cleared. 14. Antennal papilla, frontal view. 15. Apex of right dorsal tubercle of abdominal segment 4 . 


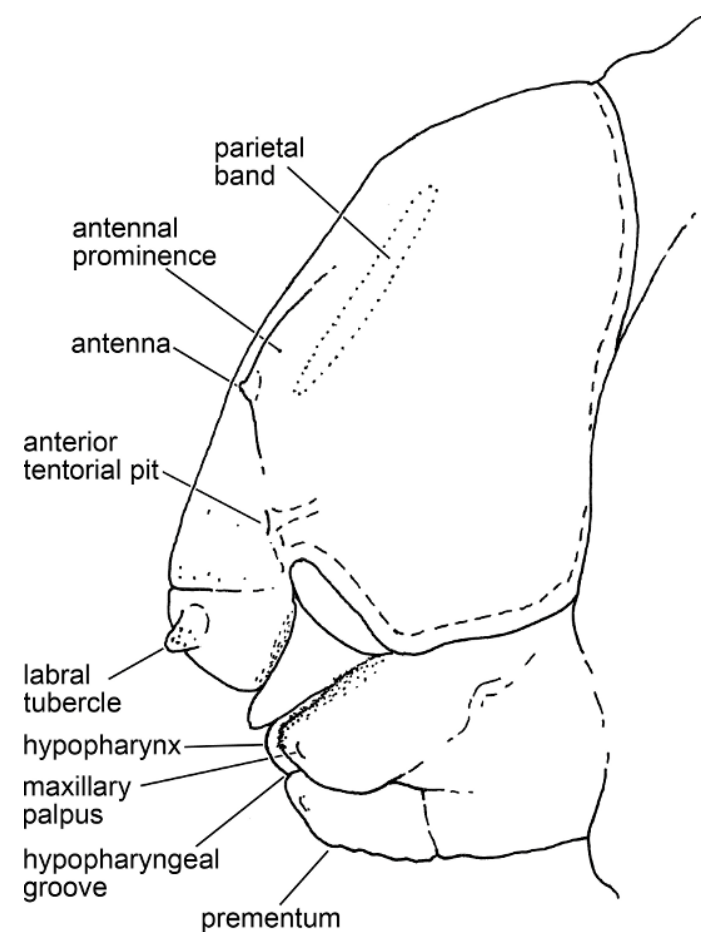

Fig. 18. Diagram of head of mature larva of Calliopsis zebrata, lateral view; verrucosities of labiomaxillary region not depicted.

scured by maxillary integumental verrucosities. Labium weakly divided into prementum and postmentum; premental sclerite not evident; labial palpus small, scarcely projecting. Salivary opening (figs. 10, 11, 19, 20) a Ushaped slit subtending hypopharyngeal groove, without lips; salivary duct attached to bottom of U; area bounded by U-shaped slit and hypopharyngeal groove apparently slightly produced. Hypopharynx protuberant, projecting forward, more or less as far as labial apex.

BoDy (figs. 8-12, 15-17): Integument with fine, scattered, nonsetiform sensilla and with spiculate areas as follows: prothorax (figs. 10 $12,19)$ with large rounded to sharply pointed spicules densely and uniformly arranged on dorsal and lateral surfaces; these spicules gradually becoming fine on lower sides of body and ventrally; other body segments with spicules fine, inconspicuous, often evenly spaced, but absent on lateral body surfaces. Body form (figs. 8, 9) moderately robust; intersegmental lines moderately weakly incised on predefecating form; on postdefecating form
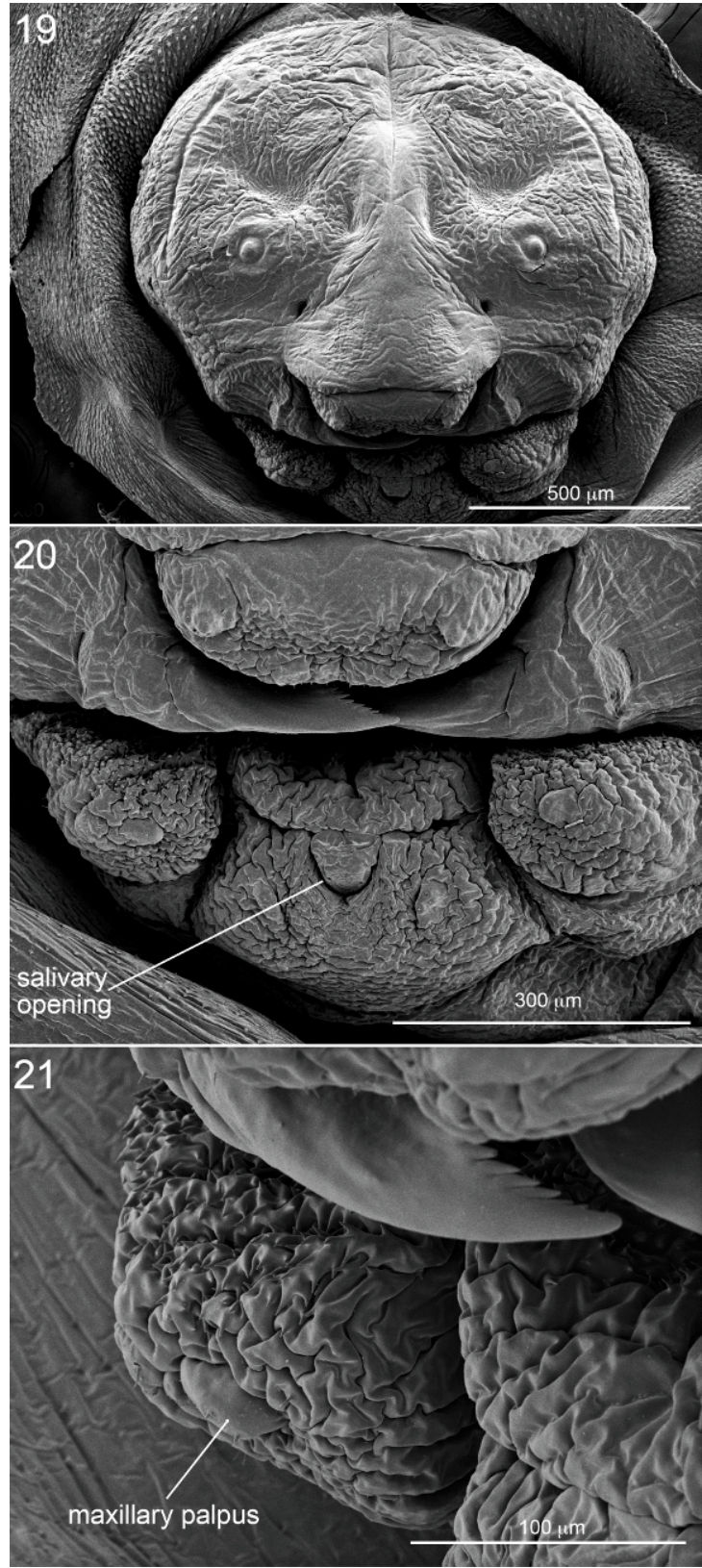

Figs. 19-21. SEM micrographs of Calliopsis $z$. bobbae. 19. Head of predefecating larva, frontal view. 20. Close-up of mouthparts of same, frontal view. 21. Close-up of right mandible, maxilla, and hypopharynx, frontolateral view, showing fine teeth along dorsal apical edge of mandible and spicules on dorsal surfaces of hypopharynx and maxilla. 
ventral intersegmental lines more pronounced; dorsal intrasegmental lines not evident; paired dorsal tubercles present and moderately large on all thoracic segments and on abdominal segments $1-6$, but diminishing on abdominal segments 7 , more so on 8 , and scarcely noticeable on 9; all tubercles conical (contrasting with transverse tubercles of Halictinae) but with basal transverse diameters clearly greater than basal longitudinal diameters; apices of midbody segments (abdominal segments 3 and 4) of some postdefecating larvae tending to be slightly flattened (fig. 15), presumably an artifact of body weight, as has been observed with other taxa having paired dorsal tubercles (Rozen and Özbek, 2008); integument of apices (fig. 15) wrinkled, weakly verrucose, contrasting with dorsal integument elsewhere; abdominal segment 9 not produced ventrally; abdominal segment 10 positioned medially on 9 as seen in lateral view (figs. 8, 9); anus apical on 10. Spiracles small, subequal in size, not on sclerites or tubercles; peritreme (figs. 16, 17) present, moderate in width, about as wide as diameter of atrial opening; atrium projecting beyond body wall, with rim, globose; atrial wall smooth (without denticles or ridges); primary tracheal opening with collar; atrium in lateral view (fig. 17) small relative to width of subatrium; subatrium long, consisting of about 20 chambers. Male with median, transverse integumental scar on venter of abdominal segment 9; female with two pair of small circular scars on venter of abdominal segments 8 and 9, with those on 9 closer than those on 8 .

Material Studied: Seven postdefecating, 1 predefecating larvae, AZ: Coconino Co.: Flagstaff, VIII-30-2007 (J.G. Rozen); 3 postdefecating larvae, OK: Blaine Co.: Watonga: Roman Nose State Park, V-18-1977 (C.D. Michener).

REMARKS: The wrinkling and fine verrucosity of the head integument, particularly noticeable on the apices of the labiomaxillary area is apparently characteristic of most Calliopsis in that is found in exemplars of Nomadopsis s.s., Micronomadopsis, Calliopsis, Calliopsima, and probably others, as well as elsewhere in the Panurginae. This feature was unexpected and needs further study.

\section{ACKNOWLEDGMENTS}

I thank Charles D. Michener, Division of Entomology, Natural History Museum, University of Kansas, for loaning the specimens of Calliopsis z. zebrata that he collected in Oklahoma, and I gratefully acknowledge the assistance of Margaret Rozen in studying the nesting site and collecting adults in Flagstaff. Molly G. Rightmyer, Department of Entomology, Smithsonian Institution, identified the specimen of Triepeolus pectoralis. Michelle M. McMahon and M.J. Sanderson, Department of Plant Sciences, University of Arizona, kindly identified Astragalus humistratus from the nesting site in Flagstaff.

Christine LeBeau, Scientific Assistant, American Museum of Natural History (A.M.N.H.), assisted in various ways and took the micrographs of the larvae using the Hitachi SEM. SEM studies were carried out in the Microscopy and Imaging Facility at the A.M.N.H. with the able assistance of Emily Griffith and Rebecca Rudolph, Laboratory Managers. Steve Thurston, Senior Scientific Assistant, A.M.N.H., took the macrophotographs (figs. 1-3, 8, 9) and composed all illustrative material for publication.

I extend thanks to Charles D. Michener and two anonymous reviewers for their suggestions on how to improve the manuscript.

\section{REFERENCES}

Cockerell, T.D.A. 1915. Habits of Spinoliella zebrata (Cresson). Entomological News 26: 366.

Hicks, C.H. 1936. Nesting habits of certain western bees. Canadian Entomologist 68: 47-52.

Michener, C.D. 2000. The bees of the world. Baltimore, MD: Johns Hopkins University Press, 913 pp.

Rightmyer, M.G. 2006. A phylogenetic analysis of the bee tribe Epeolini, with a review of the genus Triepeolus. Ph.D. dissertation, University of Kansas, Lawrence.

Rozen, J.G., Jr. 1958. Monographic study of the genus Nomadopsis Ashmead (Hymenoptera: Andrenidae). University of California Publications in Entomology 15: 1-202.

Rozen, J.G., Jr. 1959. A new species of Nomadopsis and notes on some previously described ones (Hymenoptera, Andrenidae). Proceedings of the Entomological Society of Washington 61: 255-259. 
Rozen, J.G., Jr. 1963. Notes on the biology of Nomadopsis, with descriptions of four new species (Apoidea, Andrenidae). American Museum Novitates 2142: 1-17.

Rozen, J.G., Jr. 1992. Systematics and host relationships of the cuckoo bee genus Oreopasites (Hymenoptera: Anthophoridae:
Nomadinae). American Museum Novitates 3046: $1-56$

Rozen, J.G., Jr., and H. Özbek. 2008. Immatures of rophitine bees, with notes on their nesting biology (Hymenoptera: Apoidea: Halictidae). American Museum Novitates 3609: $1-36$.

Complete lists of all issues of the Novitates and the Bulletin are available at World Wide Web site http://library.amnh.org/pubs. Inquire about ordering printed copies via e-mail from scipubs@amnh.org or via standard mail from: American Museum of Natural History, Library-Scientific Publications, Central Park West at 79th St., New York, NY 10024. TEL: (212) 769-5545. FAX: (212) 769-5009. 